\title{
The Temporal Structure of Patience
}

\author{
Michael R. Kelly
}

Phenomenology's technical terminology can often seem to invalidate the natural attitude phenomenology aims to elucidate. One notable exception to this worry is Moral Emotions: Reclaiming the Evidence of the Heart, in which Anthony Steinbock remains faithful to, and profoundly elucidates, the lived-experience of moral emotions, describing the how and the what of emotive acts such as pride, shame, repentance, hope, etc. (Kelly). Steinbock's work in general reveals a practicing phenomenologist who "liberates the "matters' that we experience so that what they are ... and their very appearing are not taken for granted in the experience" (Moral Emotions 17-18). Precise and meticulous concrete analyses of the intentional structure of everyday life (the natural attitude) pervade his writings.

In his introduction to Moral Emotions, Steinbock specifically notes the importance of dwelling on the everyday:

[S]ometimes ... mundane examples ... may be elucidating ... [I]n the phenomenological method, the very simplicity and commonness of the example is no longer taken for granted in using it as an example, and to this extent, its immediacy is transcended in the direction of that which enables the situation to arise as such, toward the originality of the very banality. By bringing such common examples into focus ... we go beyond the commonness of the example, and this opens a new world of meaning ... that was taken for granted. The point is to see the fundamental ... mystery in the ordinary but now as it is taken for granted. $(21)^{1}$

Steinbock suggests a way of doing phenomenology that brings into relief those elements of life that we often live through (look past or overlook) but do not look at (Sokolowski, Introduction to Phenomenology 50). In Moral Emotions he unflinchingly gives "final appeal ... [to] what takes place in terms of the living experience" precisely by appealing to those emotive experiences that make up who we are (as persons) and how we live our lives (Moral Emotions 23, 25). This means that in, "dealing with moral emotions, deeply personal examples that go directly to the core of who we are ... [will] come to the fore" (21).

\footnotetext{
${ }^{1}$ None of this is to say, of course, that Steinbock valorizes or uncritically endorses the natural attitude. In fact, I take him to work similarly to another exemplary contemporary phenomenologist, Robert Sokolowski. As Sokolowski puts it, "The most important contribution phenomenology has made to culture and the intellectual life is to have validated the truth of prephilosophical life, experience, and thinking. It insists that the exercises of reason that are carried out in the natural attitude are valid and true. ... When phenomenology 'neutralizes' the intentionalities at work in the natural attitude, it does not dilute, destroy, upset, or ridicule them. It merely adopts a contemplative stance toward them, a stance from which it can theorize them" (Sokolowski, Introduction to Phenomenology 63).
} 
In what follows, I attempt to participate in this exercise in looking-at. To that end, I follow Steinbock's lead, for Steinbock (especially in Moral Emotions) rarely simply exposits the writings of other phenomenologists, preferring to take "leading cues" from their work in order to follow where the phenomena lead $(17,19,68,100,160)$. As phenomenology wants to "freeze-frame" lived-experience (Sokolowski, Introduction to Phenomenology 48) - to look at what we livethrough and look-through - the issue that concerns me is just how and what one 'sees' in an episode of patience or impatience. How does one's intentional directedness and correlative world apprehension change when one intends or lives in the world in patience, impatience, or some other neighboring affect? And how can articulating the temporal dimensions of the intentional structure of patience and impatience help us illuminate what is distinctive about these phenomena?

First, I present Steinbock's view of emotions and the distinction between temporal orientation, on the one hand, and temporal meaning, on the other hand, in emotive intentionality: a distinctive object-directedness to a moment in time, and a distinctive temporal-significance that transcends the mere flow of time, respectively. Second, I attempt to develop a phenomenology of patience, which Steinbock mentions briefly as an element of hope's temporal meaning (Moral Emotions 175-176). In an effort to capture those importantly mundane examples, those "deeply personal examples that go directly to the core of who we are" and that "come to the fore" in dealing with moral emotions, I experiment with a specific kind of narrative phenomenological analysis. That is, I compose a series of vignettes derived from ordinary experience and by which patience, its opposite (impatience), or some sibling stance toward the world (e.g., self-control or hurrying) might be articulated. These vignettes (and the distinction between the temporal orientation and the temporal meaning of such an affective state) help me clarify (to the extent that I am able to) the intentional structure of patience and impatience, as well as identify essential differences between them and some stances toward the world with which they might be conflated. ${ }^{2}$

\section{Steinbock, Phenomenology, and the Evidentiary Structure of Moral Emotions}

The background to Moral Emotions is Steinbock's working with and against Husserl's phenomenology of valuing and his explanation of the "composite" moments of such intentional acts that engage a higher-level objectivity. Steinbock will follow Husserl's account of these "founded" modes of experience that intend higher-level objectivities when he finds that that notion captures the phenomenon. He will, however, adjust Husserl's phenomenological analysis when he finds that it obscures a phenomenon. And this will be the case when it comes to the emotions (10$11)^{3}$

\footnotetext{
${ }^{2}$ As Steinbock writes, "The risk of such a procedure that appeals to 'my' experience as a source of description is that phenomenology might become a new exercise in autobiography. This is one reason why phenomenological does not stop at the phenomenological 'fact' of my experience, but investigates the structural, essential, or shared components of that experience. Such a process is at all possible because the eidetic structures of experience are given in the concrete facts of experience" (18). Or, again: "With its emphasis on experience, which includes linguistic experience, phenomenological reflection is trained on the way in which something is given to us and on its essential structures" (25).

${ }^{3}$ There is much to be said for the influence of Scheler on Steinbock's view of the emotions. Since I am interested in setting the stage for a discussion and application of Steinbock's original contribution to the temporal quality of emotive intentionality, I leave this to the side.
} 
Without oversimplifying, this is something like Husserl's analysis of mundane, everyday evaluative perception: everyday perception is largely evaluative, for we spend our days "taking" things as good or bad, useful or useless, beautiful or ugly, and so on (8-10). For example, the coffee smells great but is too hot to drink just yet and that is irritating; the water in the shower does not seem to be getting hot and I am exasperated; that bacon and egg on a roll gives me some pleasure after that clunky start; this chair in the library is comfy but perhaps too comfy for this sleepy guy that has some work to do. In short, in everyday engagement with the world, I perceive, judge, evaluate, etc., often quite passively and "simultaneously." Unless we break deliberately from the evaluative dimension in which we predominately engage the world - unless we methodologically execute "the reduction"-we're almost constantly living-through a willing or valuing intentionality and we almost never live-in a bare perceptual or neutrally cognitive intentionality.

Husserl held that such mundane, evaluative intentional acts are built ("founded") upon "lower-level" cognitive acts. And he thought that phenomenological reflection could identify and isolate - distinguish but not separate - such "levels" of an everyday experience. In Ideas II, Husserl presents the notion of intentionality and higher-level objectivities according to the concrete notion of attitudes. ${ }^{4}$ Different attitudes reflect different interests in the world and thus different intentional directedness. Correlatively, then, the world appears differently to different "attitudes"; objects or objectivities appear different(ly) in correlation to the different subjective acts. As the intentional act changes, each object remains just what it is - remains the same objectbut now considered differently (from a different interest, attitude, or intentional act). As Husserl puts it,

Valuing acts ... can relate to pre-given objectivities and their intentionality proves itself immediately thereby as constitutive for objectivities of a higher level ... [W] hen we, seeing the radiant blue sky, live in the rapture of it ... we are not in the theoretical or cognitive attitude but in the affective ... There is an essential phenomenological modification. (Husserl, Ideas II 9-10)

In the founding-founded relation, one straightforwardly ("first") perceives the blue sky. That (act of) perception could motivate and thereby "found" a cognitive act of contemplation, a theoretical scientific act of meteorology, an affective apprehension of awe at its vastness, or anxiety over the sky's foreboding expanse, etc. ${ }^{5}$ One reads the opening sections of that work and sees that, to use my own example - one I develop at length in what follows - the very same food appears differently to different agents given their different interests (or to the same agent at different times given that same agent's changing interests); the objective correlate that is some type of food appears differently to a rushed mother, a hungry vagrant, a refined chef, a finicky child, a nutritionist, a chemist, a knight of faith, etc. The object remains the same object-an identity across a manifold of acts that disclose and enrich (our grasp of) the objectivity of that object.

\footnotetext{
${ }^{4}$ This material in Ideas II recalls some of the account of emotions from Husserl's fifth logical investigation in his 1900/01 Logical Investigations. Scholastic quibbles about differences between the accounts in these different works would be, however interesting, beside the point of the present discussion.

${ }^{5}$ The idea is not that the cognitive act, say, perception, "causes" the evaluative act as that on which the evaluative act is founded; rather, these are the relational "moments" that phenomenological analysis can detail in explaining the complexity of everyday human engagement with the world (Moral Emotions 10).
} 
In such evaluative moments, the affects or emotions, according to Husserl, are founded on the lower level cognitive acts. ${ }^{6}$ Steinbock wants to press the "essential phenomenological modifications" that Husserl notes (coincidentally or not) occur in the shift from the cognitive to the affective attitude. Concerning valuing acts or affective intentionalities such as those that color the experience of intending a higher-level objectivity, Steinbock asks if the founding/founded relation adequately reveals their modes of givenness and that which they disclose.

It is important to reiterate that Steinbock does not reject the founding/founded structure. Rather, he questions whether such a structure discloses or obscures the intentional and evidentiary structure of the emotions - how they appear and bring the world to appearance:

At issue ... is not the founding relation .... But the fact that the emotional sphere is said to be founded in a more basic "epistemic" intentionality, meaning that emotions are to be understood as having the same kind of intentional structure, the same kind of rational import, the same kind of givenness, evidence, and so on, as the purely judicative or perceptual sort. (Moral Emotions 10)

For Steinbock, the affects and specifically the moral emotions have their own evidentiary structure (or givenness or way of manifesting) and decidedly do not submit to the founding/founded structure. In the context of the moral emotions, if the emotional act were analogous to other founded acts such as judging or perceiving, then, he writes, "to give just one example, trust would itself have to be either a kind of judgment, something founded in a decision to trust, or a blind belief" (10). Emotions, however, "constitute" a unique mode of "meaningful experience" that reduces neither to private feeling nor extensions of the founding cognitive layer (11).

The core of Steinbock's view of emotions project follows from the "Abrahamic tradition" as "clarified phenomenologically in the traditions following Max Scheler," whose value theory, in turn, drew upon a Pascalian view of the heart's reason of which (the mind's) reason knows nothing $(54,282 \mathrm{n}$. 33). To capture this dimension of the significance of emotional experience in a way that respects their "non-founded" status, Steinbock analyzes the "temporal modes of givenness ... modalizations of possibility and relation to otherness [that] suggest the order of a unique emotional sphere" (11). He writes,

If the moral emotions have their own modes of givenness peculiar to the kind of experiences they are ..., they may not necessarily map onto familiar temporal life that we see in the presentation structure of time-consciousness ... [The] process of selftemporalization does relate to these experiences as ... mine. Yet, the temporality of some of these emotional experiences is not simply founded in these presentation structures of time-consciousness ... For ... if there are experiences that exhibit different kinds of givenness and different kinds of evidence (e.g., epiphany ...), then we can at least suspect that this will hold for their temporal modes of givenness as well. (15)

The temporality of inner life-durée, if you will—always accompanies all of one's (subjective) experiences. This makes it, we might say, trivially true that one's emotions unfold over time- just as any experience of seeing, believing, willing, eating, washing, etc., unfold over time. As I understand Steinbock, the temporality of the emotions does not map as neatly onto the familiar temporal life as does the temporality of more cognitive, volitional, or practical acts. Let us consider

${ }^{6}$ The affects and emotions are themselves "markers," if you will, of the evaluative-act, i.e., they disclose the act of valuing something such as liking or disliking. 
each, in turn, briefly.

The temporality of perception entails, say, a future passing through the present and retained in the past of that distended present of the act of perception (until such time that the "event's" relevance ceases). Think of listening to a sentence or seeing a plane fly off into the horizon. Such an experience has a future, present, and past that "flows" according to our familiar temporal life and sense of time. The sentence or object comes into the present and passes out of the present in such a way that when the sentence is done or the aircraft leaves our plane of vision, the event, which was aimed at (oriented to) the distended present, is completed. In ordinary discourse, the meaning of such a cognitive act is also in the distended present. ${ }^{7}$ An act of imaging likewise maps onto the familiar temporal flow of life. Even if what one images is imagined to be in the past, in the future, or in the "once upon a time of never-never land," the act of imagining unfolds and spans a past, present, and future that comprises the distended present of an act of imagining.

The manner in which time factors into emotive intentionality differs, however, from this familiar flow of temporal life. Surely, the basic temporal flow abides in all emotive experiences. But the temporality of emotions is not always as straight-forward as one might think on casual encounter in the natural attitude (or in an intentional directedness in the natural attitude upon which the phenomenologist reflects within the reduction). To take an example Steinbock uses very effectively, I can "live [regret] as something I already anticipate," whereas I "cannot anticipate repentance" $(25,143)$. The bedrock of internal time-consciousness in the living-present continues to flow, but at the higher level of object-directed intentionality (including both the noetic act and correlative noematic object) we can see that, on closer examination, these two emotions intend the past and future differently (a point to which I shall return to in a moment). In order to bring into relief these different modes of evidence (ways of givenness) of emotions, i.e., to capture the distinctive evidentiary structure of the affective life with its essential modifications, Steinbock draws on the distinction between the temporal orientation and temporal meaning of these moral emotions $(15,93)$.

The distinction between the temporal orientation and temporal meaning of an (emotive) intentionality is not merely a distinction between "objective time" and "subjective time"- e.g., between the time of the class measured by the clock and the time the student felt the class to take (either much longer or much shorter than fifty minutes). It is more like a distinctive objectdirectedness to a moment in time and a distinctive temporal-significance that transcends the mere flow of time, respectively. To clarify the distinction a bit, let us first consider the difference between remembering and recollecting (two active types of intentionality built off that familiar flow of temporal subjective life). Remembering is an act that is oriented toward the past and retrieves a past from out of one's life (or the more broadly historical past). Remembering refers the present to the past without any futural meaning precisely because the act of remembering changes the temporal index of the experience and gives the retrieved past as past. The giving of the past as past is the temporal meaning and orientation of an act of remembering. Remembering still closely maps onto the familiar flow of our temporal life (as we can grasp when we note that it goes toward and is about the past and not, as in anticipation, the future). Recollection is an act that is oriented toward the past and retrieves the past for the present (though also not necessarily with any futural meaning). The act of recollection does not give a changed temporal index but refers

\footnotetext{
${ }^{7}$ This might not be the case exactly with sentences expressed in cynical talk, Freudian slips, implied literary references, coded language, etc., for such expressions modify ordinary discourse through some willed nuance on meaning.
} 
the past to the present in its relevance for the now, thus giving the past as present or with a present meaning or significance. Recollection, too, still maps closely onto the familiar flow of our temporal life although not as neatly as or simply as memory (or anticipation).

Steinbock thus notices that emotive intentionality itself beckons a distinction between the temporal orientation and temporal meaning of such experiences, a distinction that aims to capture in full the intentional and evidentiary structure of the emotions. ${ }^{8}$ In some emotion experiences, though the temporal orientation and meaning may differ, this is not a subjective difference but one essential to the experience itself. Taking the case of repentance is helpful at this point, for we can build a phenomenological analysis of repentance from the difference between remembering and recollection just presented. When I remember something, I, in the now, lift that past moment from time so that it can be considered (in this) now as it appears as past (138). When I recollect something, I, in the now, lift that past moment from time so that it can be considered $a s$ it refers, relates, applies, etc., to the present. We may distinguish repentance from remembering and recollection, then, by noting that "repentance is an act ... that modifies the meaning of that past event or present self" (139). Although repentance needs a past misdeed and needs to bring that past misdeed back into the present, it is about the future. Remembering does not modify the past meaning but considers it; recollection does not modify the past meaning but applies it to the present. Repentance, however,

approaches the past ... with a new heart so that its occurrence can have a new meaning in relation to a future in which I am differently directed. The temporal meaning of repentance is futural ... This does not mean that the past changes, but its meaning, the how of its givenness as it bears on me now and who I can become [in the future] is transformed. $(140,146)$

One misses something essential about the experience of repentance without seeing that repentance, while "caused" by a past action or inaction now brought into the present, extends into the future. Repentance essentially concerns a commitment both to do penance for the past act and to recreate the penitent one's self henceforth. Without the "henceforth" characteristic of how repentance relates to the past deed, we would have a different intentional act such as remorse, regret, guilt, denial, etc. (139-144).

The distinction between the temporal orientation and the temporal meaning of an emotion thus "liberates the phenomenon" in question so that the phenomenologist can put its fullness on display (17-8). One can identify readily the temporal orientation of an emotion (e.g., anger is oriented in the now, resentment in the past, hope or despair in the future, etc.). But the temporal meaning (significance) of the emotion can be 1) harder to track despite 2) being more "meaningful" for grasping that particular phenomenon.

This proves a very useful distinction, for some emotions that appear "like" other affective conditions can be best differentiated by considering the manner in which those emotions intend the past, present, and future. If we can capture the different temporal orientation and temporal meaning of patience and impatience, then perhaps we can use the same methodological distinction to pull patience apart from self-control or impatience apart from hurrying.

Indeed, Steinbock briefly discusses patience as an affective state that essentially modifies

\footnotetext{
${ }^{8}$ As Steinbock rightly notes, “...almost all works on the emotions do not take up the unique temporal orientations and meanings of the emotions ..." (15).
} 
how one values the present in which one's wish ${ }^{9}$ is deferred; an act of patience displays a distinctive temporality. Steinbock identifies patience as "the temporal character" of hope: "[Hope's] temporal character is ... an 'awaiting-enduring'. This awaiting is an openness and an endurance, what we could also term a patience" (175). I especially want to develop this transcending dimension of patience - its openness beyond the self and commitment to some future good-which Steinbock further explains as not simply waiting around "but a mode of comportment that is precisely in opposition to my actively assuming control of the situation" (175). Both the patient and the impatient person find that time is moving too slowly, or that it has been interrupted. But patience is not only about waiting; it is an "open" mode of awaiting or engaging. Concerning patience, I want to try to capture its essentially futural significance (temporal meaning) and its present response (temporal orientation) - its openness in awaiting or engaging. The temporal orientation of patience is in the now but its temporal meaning transcends that now. Patience is oriented toward the present (in its calm awaiting or engaging) but it is "about" (its temporal meaning reflects) a committed wish for some future good (the preservation going forward of some present good or the realization of a good that has not yet come). The patient person wishes for some future now delayed or deferred by some interruption, obstacle, requirement, etc., and she now waits calmly, with equanimity and an understanding of the value of some good that transcends her own rational desire and the timely satisfaction of it. By contrast, the agent's desire to actively assume control-however impotent (as, say, a verbal grousing that does nothing except utter discontent) - will reflect impatience, which, I shall claim, is riveted to the present and the present that frustrates the self's realization of its wishes.

To help analyze the temporal orientation and meaning of patience, I next experiment with a type of narrative phenomenology (an extended example involving a care-giver and one of those aforementioned "deeply personal examples that come to the fore" in dealing with moral emotions).

\section{The Temporal Orientation and Temporal Meaning of Patience}

She would sit there, early in the day, sifting through beans - hundreds of lentils-removing the tiny pebbles. There were other interests she could have been pursuing, certainly more chores or more creative activities that recalled a passion forfeited long ago. She once designed and tailored gowns in a Paris boutique. Using other beans surely could have gotten her faster to the more creative act of cooking.

I asked her, one day, “Aren’t canned beans just as good?" She assured me they were not. The canned versions lacked the quality and flavor she could bring to the beans prepared this way. If she sifted, soaked, and cooked them in her way, they'd have increased nutritional value and flavor, decreased salt content, better consistency (neither too hard nor too soft), etc. It was very important to her to prepare the lentils this way; such preparation would make it more likely that her grandchildren would like them, eat them, develop good eating habits, and so on.

\footnotetext{
${ }^{9}$ I use the term 'wish' in an expansive sense, here. The notion of 'wish', as I am using it, would include less active acts such as longing, pining, or hoping, to name a few. The notion of 'wish' is used in a broadly Aristotelian sense as Sokolowski discusses it. A wish is a "rational activity," an "intelligent desire," a "rational wanting." (Sokolowski, Phenomenology of the Human Person 248, 239).
} 
You might think she was simply particular or meticulous. Maybe you would be right. But I marveled at the patience with which she aimed toward - to realize - so many (and distinctively human) goods, pursuing without irritability the tedium and time required to sort pebbles from lentils. There were literally hundreds of beans. And she couldn't have left a single stone.

Following her explanation, I confessed to her that she had way more patience than me. I expect that, for me, time would have seemed as if it were moving quite slowly (as it does for one anxious for the outcome or just to get on with another task).

Sorting beans was the first part of the preparation of meal. The sauce was next.

We'd have to heat the oil slowly, she'd remind us as she attended precisely to the flame beneath the pan. She set that flame the way a mother precisely and gently combs into place the child's last piece of hair before sending her off for the day. While the onions cooked, we would slice the garlic. Each part of the garlic, she would insist, had to be sliced as closely as possible to equal scale. Those thicker and thinner pieces of garlic would cook at different rates, and we could not have that if we wanted the sauce we wanted. She would saute those almost symmetrical pieces of garlic slowly over that low flame, waiting as the heat evenly brought the oils of the garlic to fuse with the oil that would bring these flavors and their qualities throughout our sauce. As she showed no haste in preparing the sauce, it made sense to let it simmer the amount of time it would need, the amount of time necessary to give the elements the time they need to become, from their separate parts, one sauce with just the right flavor.

Those of us waiting to eat often would lack patience at this point even if we could demonstrate some self-control. After all, the simmering sauce was close enough to complete, and its scent, permeating the house, urged us to dunk that good Bronx bakery bread. She would try a small piece just to assess the sauce, but we were having appetizers.

There's a type of patience in doing (sorting beans, preparing and sautéing garlic) and a type of patience in waiting (for that slow flame to heat the oil and garlic, for the sauce to be done well and really ready). Patience is not just waiting without agitation, but it can disclose a way of doing what needs to be done without being irritated that it must be done or with the time it takes for it to be done. ${ }^{10}$ The patient person can experience (the) time (something takes) differently than the person without patience (for whom time seems to be going too slowly).

With the meal ready, if the kids would not eat the beans, she would offer the red sauce over pasta. If they would not eat even that, she never got flustered. In instances that tested my patience, if the kids rejected these options in a fresh or whining way, she would calmly ask what else she could offer. After a day of all that work, I would leave the room. I did not have the patience, and by walking away I made that unwelcome scenario go away (leaving another good more to chance than one should like). She, on the other hand, calmly asked what else she could get them.

Reflecting on the whole experience of her preparing a meal to feed and care for her family, she had revealed the good of patience across a number of types. In addition to the two just mentioned (i.e., patience in doing and patience in waiting) there is even a kind of patient waiting that does not entail satisfying my desires but waits calmly as another comes to find for herself the

\footnotetext{
${ }^{10}$ See Kupfer, "When waiting is weightless" 273 . Kupfer does not expressly identify this feature of patience beyond waiting, but I think his account clearly implies and entails it.
} 
good. ${ }^{11}$ For example, one could think of the child that she hopes will come to settle on eating something or the student that the teacher must let struggle toward the answer that she must find for herself or on her own. Whatever we can say about patience, her behavior and attitude suggest that patience reflects a commitment to (and pursuit of) a good valued more than the immediate (or timely) satisfaction of one's desires (and even one's desire that some good come to pass for another).

You might want to find in her actions some meticulousness, fortitude, determination, perseverance, self-control, endurance, or tolerance. And you might be right. But I want to say that whether she wished something away (the crying, finicky, spoiled behaviour), whether she wished something otherwise (that her grandchildren would one day adopt a healthful diet), or whether she paced herself preparing the sauce or pursued without irritation the tedium of sorting those pebbles, she manifested patience.

In all of these scenarios, patience entails a response of, or comportment with, calm or equanimity in the face of either 1) some present $\mathrm{X}$ that interrupts, delays, or defers, some future good for which one wishes, or 2) some present $X$ with which one must tarry or which one must discharge on the way to fulfilling one's wish (some intermediate activity such as preparing the garlic in order to make the sauce in order to X). ${ }^{12}$ Since patience is not just about waiting without agitation but also about doing without agitation what must be done, we can say that the patient person does such good things well (both attitudinally and technically). The patient person cultivates that good of character that aids one in, and is indeed aided by, keeping in view some good that transcends the desire to have one's desire presently satisfied. To use one of Aristotle's turns of phrase, it is by waiting or doing without agitation that we become patient, and it is when we have become so that we are most able to wait or engage well. ${ }^{13}$ How, then, does the patient person intend the world? And what does she "see" in — what is the lived-experience of - an act of patience?

Standard views of patience in contemporary western philosophy seem to emphasize the place of the present in an act of patience. Kupfer defines patience as "the disposition to accept delays in satisfying our desires," noting more specifically that "patience is not just waiting but waiting without agitation" (Kupfer 265). Pianalto refines that definition a bit, noting that "we could ... define patience as the capacity to endure temporary or permanent frustration of our desires without lapsing into anger or despair," for patience is "the virtue of bearing one's unavoidable or wisely assumed burdens with equanimity" (Pianalto, "In Defense of Patience" 3, 4). On such views, the temporal meaning and temporal orientation of patience seems to be the present, for it is a disposition, a virtue - i.e., a state, that enables the agent to have calm in waiting when facing 1) or 2). Impatience, by contrast, is marked by a frustrated or irritated reaction focused in the now on what (at this moment in time) delays or interrupts my realization of what I wish for (Kupfer 266, 268). One could express impatience over that which one desires but is not yet here (e.g., the sauce that is not really ready) or over the presence of what one does not desire that has not or will not yet go away (e.g., whining behaviour). The temporal orientation and meaning of an act of

\footnotetext{
${ }^{11}$ Thanks to Christopher Arroyo for pushing me on this point and helping me see this distinct type of wishing.

${ }^{12}$ For a good account of patience, see Pianalto, "In Defense of Patience".

${ }^{13}$ It seems worth nothing that this is not to say that patience is about temperance, which actually entails forming appropriate and sometimes moderate or weak desires regarding only sensual pleasures, as Aristotle's discussion of temperance makes clear.
} 
impatience is a reaction in the present against the time it takes to do the $\mathrm{X}$ required to achieve $\mathrm{Y}$ or the time during which some unwilled and undesired interference persists.

On these standard views, patience and impatience both would appear to be directed toward or focused on the present. What would distinguish these two opposite affective states, then, would be the absence of (negative) affect (in patience) or the presence of (negative) affect (in impatience) - a response or reaction, respectively, to 1) or 2). Each response or reaction (i.e., patience or impatience, respectively) recognizes 1) or 2) and orients itself in the now with a focus on 1) or 2). As patience sees 1) or 2), it does not alter the subjective sense of time to make it appear to pass too slowly. The opposite is the case for impatience (often, thus, adding to the agitation). Why might this be so?

I agree with the standard views that the temporal orientation or focus of patience is in the now as the patient person faces without irritation something that delays the satisfaction of her desires by trying, testing, demanding, requiring, interrupting, etc. I agree, too, that the phenomenon of patience first and most obviously appears in the agent's calm response in the now to the "presence" of 1) or 2), i.e., waiting without agitation or bearing unavoidable and wisely assumed burdens with equanimity. But I think that the meaning (significance) of that present orientation in patience is motivated by the agent's relation to some wished for future that the patient person keeps in view. Thinking, again, of my mother-in-law and how she pursued tedious tasks without irritability, or waited calmly for something to come about or pass in due time, I think the calm response of patience reflects her ability to keep in view the good to be realized in the future. The value of that future good to be realized transcends her desire to have her desires satisfied now.

The standard views of patience may emphasize the patient person's dispositional response and her focus or orientation in the now as characterized by an absence of (negative) affect in the waiting. Yet these accounts likewise imply the essentially futural significance (or meaning) of the temporal structure of patience. Kupfer's distinctions between waiting with strong or weak desires cast patience as what entails a desired future. ${ }^{14} \mathrm{He}$ notes that the patient person waits "for things to unfold" or takes "the time needed to perform tasks" (Kupfer 265). Both Kupfer and Pianalto note that a patient person does well some task without irritability over the time that task requires because she is committed to a larger end to be achieved in the pursuit of such intermediate tasks of waiting (Kupfer 267). As such, through patience, one keeps oneself, and by doing so the patient person reciprocally preservers the pursuit of some good that an impatient reaction might spoil or abandon. ${ }^{15}$ The meaning of the present orientation of patience is predicated on the wish for some future and the agent's valuing that good to be realized or preserved over the immediate or timely satisfaction of her desires. That is, the temporal meaning of patience is its commitment to the realization of some future good; its temporal orientation is the waiting or acting calmly, or without irritation, in the now.

\footnotetext{
${ }^{14}$ Of course, other states keep a desired future in view without patience, e.g., determination, perseverance, spite, grudges, hurrying.

${ }^{15}$ There is a real question about whether or not the good of patience is merely or even predominately instrumental. See David Kangas' excellent interpretation of Kierkegaard's Upbuilding Discourse (Errant Affirmations 45-67). Given the space restrictions in this paper, I cannot engage this interesting and relevant view of patience. But given Steinbock's interest in verticality and liminal phenomena, as well as his view of patience as awaiting without desire to take action and intervene, it will be interesting to carry forward this analysis in a longer piece. See Pianalto10-12.
} 
The hypothesis I am testing is that patience, unlike impatience, responds to what it recognizes in 1) or 2) in a way that preserves (keeps in view) the future for which the patient person wishes. Without such a future wish - either wishing something away, wishing for something to arrive, or wishing to preserve going toward some good to which one is committed - neither patience nor impatience makes sense (has significance, meaning). The focus (or temporal orientation) in an act of patience is, in the now, on 1) or 2). As the opposite of patience, impatience reacts to 1) or 2) in a way that loses sight of or smothers - under the desire to have one's desire satisfied now - that view of the good that the agent wants to preserve into the future or realize in the future. The impatient person lets 1) or 2) become the focus; indeed, in the present of the impatient person's reaction, there is a dual focus in the now-moment of impatience, for the impatient person intends both the interference and his desires as unsatisfied (as two sides of the same coin of impatience).

The different affects of a patient response and an impatient reaction manifest the different temporal meaning of emotive-intentionality. The absence of the negative, reactive affect in patience bespeaks the preservation of the view of the good for which one wishes (or the commitment to some good that it is valuable to preserve into the future) even beyond the "immediate" satisfaction of the agent's own wishes. The futural temporal meaning of an act of patience is the agent's attention to the good-her ability to keep in view the wished for goodand it is this attention that motivates the absence of (negative) affect characteristic of the patient response to the 1) or 2) now present. What patience bespeaks in a present in which a patient person responsively faces 1) or 2) can be said and only is said meaningfully on the condition that there exists some maintained and prioritized view of the future good for which she wishes (the value of which she places over the timely satisfaction of her wishes).

The impatient person thus differs from the patient person precisely insofar as he loses sight of - in that very lived-in moment of an act of impatience - the future for which he wishes. The temporal meaning of impatience - in that very lived-in moment of impatience - is not the unfulfilled future wished for; the temporal meaning of impatience is the agent's dissatisfaction now (in this moment) - is about the "I" and with my not having what I want because of that 1) or 2) now happening. In impatience, one is riveted to the present and to oneself in that present (Moral Emotions 175).

\section{The Temporal Orientation and Temporal Meaning of Impatience}

I do not consider myself a patient person.

I recently walked into the Department of Motor Vehicles (DMV) and saw long lines everywhere. Everywhere - as far as I could see-long lines, long faces, and slow workers.

Immediately, before really observing the pace of the cue or the workers, I groused: "This is unbelievable! I'm going to be in this dump all day! Doesn't anyone work around here? Why are they so understaffed?" Tacit, social norms likely play a role in determining the appropriateness or inappropriateness of my impatience - the "frustration at having to wait to get what we want" or to wait for what we wish for another person (Kupfer 266). Others likely would say that such circumstances or wait-times are normal and to be expected (even if we all agree that the system is flawed and needs correction) (see Kupfer 266). Especially since I had just arrived, others likely would say and be justified in saying that I should accept such circumstances with equanimity (or 
patiently). If the wait objectively begins to exceed normal or expected times such that my agitated expression were understandable, we might not even have impatience in this case; rather, we might have a case of incredulity or indignation. My initial expression of impatience may have masqueraded as indignation or incredulity. But a third-party observer could unmask my "incredulity" or "indignation" for what it was, namely, impatience.

In impatience, as Kupfer puts it, the person simply "gives in to his impulses and expresses without restraint his inability to accept friction in the meeting of his desires" (Kupfer 268). The impatient person's desire or appetite, that is, smothers his wishes (his rational desires) and collapses a rational desire into a mere wanting and wanting now (see Sokolowski, Phenomenology of the Human Person 250). Impatience is riveted to the present. That is its temporal orientation and its temporal meaning. In impatience, my desire for immediate gratification smothers the past by not allowing my understanding to contribute to a grasp of this presently unwanted interference or this set of requirements that (past) experience tells me I must discharge prior to realizing the end for which I wish. In impatience, it is as if I, in my state of frustrated desire, simply rage against the obstacle without being able to see clearly if such rage is warranted. (It rarely is.) Impatience wants to obliterate that present in order to create room now for another now-the now that (includes what) it wants right now. The impatient person cannot in the very lived-in moment of impatience any longer see (no longer "intends" or has in view) the future for which he wishes. This is because his focus is right now in the lived-in moment of impatience on the obstacle 1) or 2) and/or his frustrated wants. The impatient person closes himself off to the future by focusing right now on either the obstacle or his unfulfilled desire or both. But he is no longer focused in the moment of impatience on what he wishes for.

The person experiencing impatience, we could say, does not want some future to come. Instead, like a robust child, he wants what he wants and he wants it right now. Regarding things we have chosen-requirements and intermediate tasks rather than unwanted or unforeseen interferences - it is as if the impatient person wills to leap over the intermediary activities that need to be completed, as if his desire wills to leap into the future to make it a present now, to collapse the future into the now. Time moves too slowly or takes too long according to the impatient person's reaction. Unlike my mother-in-law, I cannot, in my impatience, see that slowly heating the oil and precisely slicing the garlic takes time so that we can realize the good of a well-made sauce. Unlike my mother-in-law, I cannot appreciate the behavior of young children as they learn how to eat well and show gratitude (as they likely one day will). And in variation from the normal understanding of events that take time, I cannot abide the lines at the DMV, which are typical and to be expected (however much we agree they could be improved). Consequently, in my impatient state, I no longer can "see" that, for example, hemming-and-hawing about DMV lines or cutting this or that corner will not, even if it were to hasten the time, result in realizing well the fulfillment of what I wish for (see Pianalto 5).

With a sense of how an impatient person is riveted to the present (how the temporal orientation and meaning of impatience is the now), we should distinguish from impatience states such as hurrying, anxious anticipation, and excited anticipation. ${ }^{16}$ Racing against time is not the

\footnotetext{
${ }^{16}$ See Kupfer 267-268. I want to develop Kupfer's good and helpful insights along the lines of the temporal orientation and temporal meaning of these affective states neighboring impatience. This is helpful because the affective states might mistakenly appear similar insofar as agitation or irritation could characterize them and we cannot distinguish emotions based on their affects.
} 
same as refusing (the) time (of waiting or the) delay found in impatience. If I realize the wait at the DMV has led to a nearing of the time when I must collect my child from daycare, then perhaps I will try to hurry things along or make other arrangements. In such a moment, it is not that I curse the present in the way an impatient person would. Rather, it is as if my hurrying conveys an attempt to hasten the arrival of the future, as if my hurrying is an expression of my wish (to be "on time"). The meaning of hurrying is in the future while its orientation is in the present.

If I find that I will be late and believe my child will become uneasy while waiting for me, perhaps a frantic kind of anxious anticipation sets in, a kind of anxious anticipation that is not hurrying or impatience, a kind that, because the outcome is uncertain and in the balance, weights the present with worry. Realizing I am late, stuck in and delayed by traffic (as we all have been), the present now drawn out and seemingly unwilling to give way to the future, I may become upset. But it would seem wrong to label as impatient my dissatisfaction. My frequent and perhaps anxious thoughts about disappointing or worrying my son are not "expressions" of impatience but something else. Something besides and more important than wanting my desire to be satisfied here and now motivated the anxious pacing, questioning, or sometimes even exclaiming. I wait with great agitation (but not impatience) for traffic to clear and my arrival to be achieved. The frustration was not over having to wait or having our (self-oriented) desires stifled. The frustration in this anxious anticipation concerned the uncertainty of the time of resolving the problem. ${ }^{17}$ The meaning and orientation of this agitation is in the future and not the present (making it unlike my DMV outburst which was about the waiting and focused on that now and myself in that now).

Let me set aside yet another affective state of anticipation that differs from and should not be confused with impatience: excited anticipation. When children excitedly ask "Are we there yet?", we teach them that these are moments that take time. As we teach children about endeavors that take time, we teach them to accept the time something takes and thus teach them patience regarding states of affairs in the world. When children ask out of boredom in a frustrated tone, we exhort them to this understanding and acceptance. Even as we age, we find that we "cannot wait" for certain events (such as vacation or the end of this meeting or the visit from a dear friend).

Unlike impatience, excited anticipation waits in the present with a heightened positive affect. The child knows on Wednesday that a friend will visit on Friday and cannot stop talking about the day to come and all the exciting things they will do. He looks forward to the future-is oriented toward the future - but in the now he expresses a wish for the impossible, namely, that time move faster, that there were less intermediate steps, or that those intermediate steps could be traversed faster: "I can't wait! It's going to be so much fun!" He does not treat this wish for the impossible as if it were possible or should be otherwise; in excited anticipation unlike impatience he expresses his enthusiasm in the now for the future that is to come and that he believes will come (rather than expressing frustration that the future is not here and is taking too long to arrive). We know that these things take time, and excited anticipation is not inapposite necessarily. The affective wish that the realization of some future desired good be hastened is simply excitement or anticipation and falls outside of the spectrum of impatience.

As such, excited anticipation differs from impatience, which reacts riveted to the now with a heightened negative affect because it wants to reject that now that stifles its desires. Excited anticipation "can't wait," while impatience "won't wait." Excited anticipation metaphorically

\footnotetext{
${ }^{17}$ Kupfer distinguishes these states according to the difference between a concern for another rather than a focus on the frustration of one's desires, which aligns with my sense of patience as riveted to the self and the present.
} 
cannot wait but it does wait because it still sees the future and is excited for or about that future (which it believes will arrive). Still focused on the future, excited anticipation does not focus on its present unfulfilled state or some present obstacle. Impatience will not wait and expresses its frustration because it "can't believe" what is happening to it now-because it is so "indignant" or "incredulous" about the interruption and its interrupted, unfulfilled desire in the now moment. The focus and meaning of impatience is the frustration of my wish and that which frustrates it.

The temporal meaning and orientation of an expression of impatience is the present; the impatient person expresses his desire for immediate gratification and refusal of the time of waiting or the time of doing that "appears" to be moving too slowly or slower than one would like. Impatience as riveted to the present refuses both the past understanding that tells one that some endeavor takes time and the future time that it takes for some activity to be realized. It focuses in the now only on the now-the object of that focus being the interruption that is 1) or 2) and/or the impatient person's presently unfulfilled desire. The impatient person thus no longer focuses in a moment of impatience on the thing for which he wishes but that remains absent or delayed because of 1) or 2). That is, the impatient person in a moment of impatience loses view of the good for which he wishes.

\section{Conclusion: Patience as a Moral Emotion Distinguished from some Siblings}

Patience is colloquially said to be a virtue. And we likely should give a nod to folk wisdom on this point. To illuminate more the way in which the patient person is oriented outside the now and perhaps also outside primary interest in realizing her own desires, I want to close by contrasting patience to some ways of orienting oneself that we might conflate with patience. In each case, the temporal meaning and orientation of these sibling stances will differ, as will the place of the "I" as self-determining or not.

The patient person is not unaware of - indeed she acknowledges - the present of 1) or 2) that is obstructing, frustrating, tedious, challenging some state or activity, etc. The patient person is thus not like the blasé or blandly "Zen" person inclined or disposed to put things in perspective as it were. ${ }^{18}$ There may be calm in the now for the blasé or blandly Zen person (again for very different reasons), but that is because there is no deep wanting and thus no waiting. The now that relates to the future still absent or an unwanted present still present is too insignificant for the blasé person and Zen person (again for very different reasons). The blasé person cares in a way too diffuse to see the now interruption or requirement as worth fretting over, while the blandly Zen person sees the now that interrupts or demands in a broader perspective that renders it too insignificant to fret over. Such characters live only in the now but the patient person acknowledges the now with an eye toward the future good to which she is committed.

The blasé or Zen person is calm in the face of some 1) or 2) because he is capable of overlooking 1) or 2) because nothing (for very different reasons) matters that much to these different characters. They may appear patient but they are not. The patient person, however, wishes for some good in the future that is now delayed or deferred by some interruption, obstacle,

\footnotetext{
${ }^{18}$ As Kupfer notes, "For people whose desires are not strong, waiting is liable to be stress free ... We may plausible question whether accepting delays when desires are weak constitutes patience at all. Since people whose desires are not strong do not care strongly about the objects of their desire, such individuals have nothing to be patient about (266).
} 
requirement, etc. She waits calmly, with equanimity, guided by an understanding of the value of some good that transcends her own rational desire and the timely satisfaction of it. No wishing for something or wishing something away, then no (a)waiting. And, if there is no (a)waiting, then there is no patience (or impatience). Unlike the blasé or blandly Zen person, the patient person cares in such a way that her caring does not prevent her from dealing calmly with adversities —or even recognizes that some event delays or interrupts her pursuit of that which she desires or wishes for another. ${ }^{19}$ The patient person cares about some good beyond the immediate or timely satisfaction of her self-oriented desires.

The patient person thus looks both at and past that present challenge-1) or 2) —with equanimity, putting things or having things in perspective, as it were. Patience differs to this extent, too, from the perhaps fervent or hostile way that one with determination or perseverance looks past a present requirement, adversity, interruption, etc. Determination confronts the present obstacle in a way that patience seems not to share. One could, of course, persevere patiently. Consider, again, my account of my mother-in-law's patience and perseverance. I had learned, only years later, that her wrists and hands were shot through with arthritis. Imagine the pain in the sorting and pinching. Imagine the frustration - the inevitable frustration - at losing a tiny pebble once plucked from the pile of tiny beans. But when I think of her arthritic hands sifting through that pile of beans so calmly, I marvel at her patience, that patience that accompanied her perseverance. I have persevered through pain to the end of certain tasks now and then, but I had done so in a largely agitated state (punctuated with and by the help of expressions I cannot record in a formal essay). In fact, when helping her one morning, I can remember being not at all pleased when I dropped pebble after pebble when sorting those tiny stones apart from those tiny beans. Not her. She would comment now and then in an almost 'matter of fact' way about the size or number of pebbles in a particular batch. But she moved without a sigh or groan or expletive (despite the occasionally sharply drawn breath by which, I figure, she took in the pain from her joints). The patient person thus surely perseveres but the persistent (determined) person does not always persevere patiently. ${ }^{20}$ Perhaps, on another occasion, it would help to think of the patient person somewhat like the tolerant person who looks beyond something one presently thinks objectionable in the name of a higher value (e.g., the son tolerates the father's racism in the name of pursuing the good of filial piety). ${ }^{21}$

Again, a patient person might look like a self-controlled person, but she is not. The selfcontrolled person experiences some inner turmoil in making the effort to not give into the nowright now-when that moment could give him what he wants. The patient person, by contrast,

\footnotetext{
19 Thanks to Christopher Arroyo for discussions on these differences.

${ }^{20}$ As the colloquial sense of persistence indicates, beyond persisting, one who is persistent is often pesty and not at all patient. Persistence thus need not entail patience, and perseverance often persists or endures with great agitation.

${ }^{21}$ The tolerant person does not move past the $\mathrm{X}$ (hoping it goes away or discharging it as one does with intermediate activities). The tolerant person knows that $\mathrm{X}$ is going to stay and tells himself that it is alright that $\mathrm{X}$ stays because in letting X stay we promote some other, more important good. The simile is not perfect because the patient person believes that the moment will pass eventually and this makes her state different from endurance or tolerance. Regarding the temperate person, I wonder, too, if he is not patient either because his desires, however calm, are focused on engaging with the now with moderation and calmness rather than waiting for the removal of something he wishes away or the arrival of something for which he wishes. Temperance is focused in the now as a deferring without waiting (unless we speak of a waiting for next time, which reveals a patience in temperance but not an equivalence between patience and temperance).
} 
would see that the sauce (for example) is not quite ready now, and she will wait calmly for the future for which she wishes. As noted above, I showed some mild self-control, I suppose, when dunking just a bit of that bread in that still-cooking sauce; but no one with self-control is patient, for self-control is predominately about the present moment in both temporal orientation and temporal meaning. The patient person focuses on a good beyond the satisfaction of her wishes as she calmly waits for the child to come to decide on dinner (for something to come to be or for something to go away). The self-controlled person may wait, but he will wait, focused on himself, with inner turmoil and with a focus on the now that keeps tempting him.

Granted, I might convince myself to refrain by reminding myself that I would come to regret reacting and interrupting my colleague, and while that is an intentional act with futural meaning (living regret in anticipation, as we have seen) that helps me restrain or control myself in the now, it is not patience. The moment of self-control either follows or accompanies that moment when my desires come to the fore, come to presence, and vie for my focus. Self-control may derive from a commitment to a greater good, but, in that moment of self-control, facing that obstacle or interference (leaving temptation aside) the self-controlled person toils with just that now that he could or could not take, eliminate, avoid, etc. The self-control in this instance is all about the instant now and not about the future. I have this urge now that I could satisfy right now. Indeed, even if I control myself thanks to futural considerations (in the form of anticipatory regret), the self-control in the present causes me some bother to choose to not have it now when I could have it now. There is no self-control in patience, for the latter is liberated from the present because it transcends itself while the former struggles with two wishes held in tension (and thus is condemned to itself and the now in which it finds itself frustrated).

Whatever is one's view of patience as a virtue or what type of virtue it is, patience fits, I think, Steinbock's conditions for what makes for a moral emotion. One of the central features of moral emotions, on Steinbock's terms, is that they reveal something about the nature of persons as "inherently interpersonal" and "intrinsically relational and not self-grounding" (Moral Emotions 12). Whatever else the moral emotions reveal, they reveal that I am (one is) not "completely selfdetermining" (54). It is perhaps this feature of moral emotions that distinguishes patience from impatience more than anything else. Whatever else my analyses of patience and impatience show, they reveal an essential difference between these emotions on this score. An impatient person or act decidedly reflects one's belief that one is self-determining while a patient person or act does the opposite. We could say of impatience what Steinbock says about pride, namely, "I live myself as the major, predominate, or sole constitutive source in the presence of others as excluded" (47). The patient person lives in such a way that she is "engaged with the outcome" as valued beyond (but not the exclusion of) the satisfaction of her own desires (166).

\section{Works Cited}

HUSSERL, Edmund. Ideas Pertaining to a Pure Phenomenology and to a Phenomenological Philosophy. Second Book: Studies in the Phenomenology of Constitution. Trans. R. Rojcewicz and A. Schuwer. Dordrecht: Kluwer, 1989.

KANGAS, David. Errant Affirmations: On the Philosophical Meaning of Kierkegaard's Religious Discourses. London: Bloomsbury, 2018. 
KELLY, M.R. "A journey through the emotions into a new existentialism: a review of Anthony J. Steinbock: Moral emotions: reclaiming the evidence of the heart." Continental Philosophy Review 49.4 (2016): 533-544.

KUPFER, Jordan. "When Waiting is Weightless.” The Journal of Value Inquiry 41 (2007): 265280.

PIANALTO, Matthew. "In Defense of Patience." (2012):

https://eku.academia.edu/MatthewPianalto

SOKOLOWSKI, Robert. Introduction to Phenomenology. Cambridge: Cambridge University Press, 2000.

-. Phenomenology of the Human Person. Cambridge: Cambridge University Press, 2008.

STEINBOCK, Anthony. Moral Emotions: Reclaiming the Evidence of the Heart. Evanston: Northwestern University Press, 2014. 